\title{
Parcelamento da adubação nitrogenada na cultura do milho irrigado em sistema plantio direto
}

\author{
Simério C. S. Cruz ${ }^{1}$, Francisco R. da S. Pereira ${ }^{1}$, José R. Santos ${ }^{2}$, Abel W. de Albuquerque ${ }^{2}$ \& Edson T. da Silva ${ }^{3}$
}

\begin{abstract}
RESUMO
Objetivou-se, neste trabalho, avaliar a melhor época de aplicação do $\mathrm{N}$ em cobertura para a cultura do milho irrigado em sistema plantio direto, no Estado de Alagoas. Foram utilizados três híbridos de milho (TORK, FORT e BRS-3003) e quatro épocas (dias após a semeadura - DAS) para adubação nitrogenada de cobertura, compreendendo os seguintes tratamentos: 1) $120 \mathrm{~kg} \mathrm{ha}^{-1}$ aos $15 \mathrm{DAS}$, 2) $60 \mathrm{~kg} \mathrm{ha}^{-1}$ aos 15 DAS e $60 \mathrm{~kg} \mathrm{ha}^{-1}$ aos $30 \mathrm{DAS}$, 3) $120 \mathrm{~kg} \mathrm{ha}^{-1}$ aos $30 \mathrm{DAS}$, 4) $60 \mathrm{~kg} \mathrm{ha}^{-1}$ aos 30 DAS e $60 \mathrm{~kg} \mathrm{ha}^{-1}$ aos 45 DAS e 5) a testemunha sem adubação nitrogenada. O delineamento estatístico foi em blocos casualisados com quatro repetições em esquema de parcelas subdivididas. Os componentes da produção estudados foram: população final de plantas ha-1 ${ }^{-1}$ número de espigas ha-1 ${ }^{-1}$ comprimento de espigas, número de fileira de grãos por espigas e massa de 1000 grãos. As produtividades de grãos obtidas não apresentaram diferenças significativas entre os tratamentos que receberam adubações nitrogenadas, independentes da época de aplicação e parcelamento utilizado; conclui-se, portanto, que o parcelamento da adubação nitrogenada de cobertura não se faz necessário no sistema plantio direto, no Estado de Alagoas.
\end{abstract}

Palavras-chave: componentes da produção, épocas de aplicação de N, manejo do solo

\section{Split application of nitrogen in irrigated corn crop under no-tillage system}

\begin{abstract}
The purpose of this study was to evaluate the best time for application of $\mathrm{N}$ for an irrigated corn crop in a no-tillage system in the State of Alagoas. Three corn hybrids were used (TORK, FORT and BRS-3003) with four application times (days after sowing - DAS) for fertilizing with nitrogen as top dressing, consisting of the following treatments: 1) $120 \mathrm{~kg} \mathrm{ha}^{-1}$ at $15 \mathrm{DAS}$, 2) $60 \mathrm{~kg} \mathrm{ha}^{-1}$ at $15 \mathrm{DAS}$ and $60 \mathrm{~kg} \mathrm{ha}^{-1}$ at $30 \mathrm{DAS}$, 3) $120 \mathrm{~kg} \mathrm{ha}^{-1}$ at $30 \mathrm{DAS}$, 4) $60 \mathrm{~kg} \mathrm{ha}^{-1}$ at $30 \mathrm{DAS}$ and $60 \mathrm{~kg} \mathrm{ha}^{-1}$ at 45 DAS and 5) control treatment without $\mathrm{N}$ fertilization. The experimental design was in randomized blocks with four replications in a subdivided plot scheme. The components of the production studied were: final population of plants ha-1 ${ }^{-1}$ numbers of corn ears ha-1 length of corn ears and number of rows of grains of corn and mass of 1000 grains. The productivities of grains obtained did not present significant differences among the treatments that received fertilization with nitrogen, independent of the time of application and number of split applications. It is concluded that in the notillage system in Alagoas spliting the manuring with nitrogen (top dressing) is not necessary.
\end{abstract}

Key words: yield components, $\mathrm{N}$ epoch application, soil management

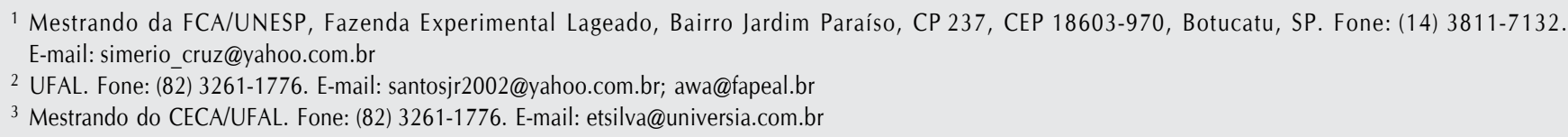




\section{INTRODUÇÃO}

Dentre os elementos essenciais para o crescimento das plantas, o nitrogênio deve ser destacado, em virtude de ser o mais caro e requerido em maiores quantidades pela maioria das culturas, principalmente o milho. Resultados experimentais obtidos por vários autores, sob diversas condições de solo, clima e sistemas de cultivo, mostram respostas generalizadas do milho à adubação nitrogenada, sendo que cerca de 70 a $90 \%$ dos ensaios de adubação com milho realizados em campo, no Brasil, respondem à aplicação de nitrogênio (Cruz et al., 2005).

Para se obter rendimentos elevados de milho (Zea mays L.), é necessário aplicar fertilizante nitrogenado visto que, em geral os solos, em geral, os solos não suprem a demanda da cultura em termos de nitrogênio nos diversos estádios de desenvolvimento da planta (Pöttker \& Wiethölter, 2004). As recomendações atuais para adubação nitrogenada em cobertura na cultura do milho variam para o cultivo irrigado, entre 120 a $150 \mathrm{~kg} \mathrm{ha}^{-1}$ (Souza et al., 2003).

A época de aplicação de $\mathrm{N}$ pode variar, sendo comum a aplicação, na semeadura, de parte do $\mathrm{N}$ recomendado e o restante em cobertura, quando as plantas apresentam de 4 a 8 folhas (Pöttker \& Wiethölter, 2004).

No Brasil existe o conceito generalizado entre técnicos e produtores de que, aumentando-se o número de parcelamento da adubação nitrogenada, aumenta-se também a eficiência do uso do nitrogênio e se reduzem as perdas, principalmente por lixiviação (Coelho et al., 2006).

Sabe-se que a absorção de $\mathrm{N}$ ocorre durante todo o ciclo vegetativo do milho e, apesar das exigências nutricionais serem menores nos estádios iniciais de crescimento, pesquisas indicam que altas concentrações de $\mathrm{N}$ na zona radicular são benéficas para promover o rápido crescimento inicial da planta e o aumento na produtividade de grãos (Silva et al., 2005).

A absorção de nitrogênio pelo milho é mais intensa no período de 40 a 60 dias após a germinação, mas a planta absorve pequena quantidade na germinação e após o florescimento caracterizando, desta forma, três fases para absorção: uma fase no crescimento inicial lento (germinação) uma fase no crescimento rápido em que 70 a $80 \%$ de toda matéria seca são acumulados, e uma última fase de absorção cujo crescimento é novamente lento, acumulando cerca de $10 \%$ de massa de matéria seca total da planta (Magalhães, 1979; Machado et al., 1982; França et al., 1994; Haper \& Shape, 1995; Vasconcelos et al., 1998); entretanto, não se dispõe de dados para recomendação de adubação nitrogenada para a cultura do milho no Estado de Alagoas, mormente no sistema plantio direto, que é um sistema pouco utilizado no Nordeste do Brasil; sabe-se, contudo, que a utilização de sistemas de manejo com menor revolvimento do solo promove maior atividade biológica, aumento nos teores de carbono orgânico, N total e outros nutrientes (Bayer et al., 1997); todavia, o não-revolvimento do solo promove modificações na ciclagem dos nutrientes, sendo o $\mathrm{N}$ o mais afetado, uma vez que, com a decomposição mais lenta dos resíduos vegetais deixados na superfície do solo, processos de imobilização, mineralização, lixiviação, volatilização e desnitrificação, são alterados (Lara Cabezas et al., 2000), recomendado-se, então, aplicações de doses de N 20 a 30\% maiores na semeadura no sistema plantio direto (Müller Mai, 2003).

Conforme Sá (1993) a maior perda de N no SPD pode ser compensada pela liberação lenta e gradual do material orgânico. Uma alternativa para minimizar o problema, segundo Gonçalves et al. (2000), é manter sempre o solo com cobertura vegetal, com a função de reciclagem de nutrientes na sua biomassa e de cobertura do solo.

Segundo Rambo et al. (2004), o manejo correto da adubação nitrogenada é fundamental nos princípios da agricultura de precisão, visando aumentar a eficiência de uso do N; desta forma, a avaliação do efeito da adubação nitrogenada em cobertura na cultura do milho é uma prática importante no contexto da fertilização de plantas, contribuindo para a minimização dos custos de produção; contudo, ressalva-se que a eficiência da adubação depende, dentre outros fatores, das condições climáticas, do tipo de solo e da capacidade de extração de nutrientes pelas plantas, durante o cultivo (Neumann et al., 2005).

Objetivou-se, através deste trabalho, avaliar a melhor época de aplicação do $\mathrm{N}$ em cobertura para a cultura do milho em sistema plantio direto, no Estado de Alagoas.

\section{MATERIAL E MÉTODOS}

O experimento foi realizado durante o ano agrícola de 2004, na Área Experimental do Campus Delza Gitaí, pertencente ao Centro de Ciências Agrárias - CECA, da Universidade Federal de Alagoas - UFAL. As coordenadas geográficas de referência, são: Latitude Sul 9²9' 45” e Longitude Oeste $35^{\circ}$ 49' 54"; a altitude do local do experimento é 165 m com 3\% de declividade.

$\mathrm{O}$ solo em que as parcelas experimentais foram instaladas, foi classificado como Latossolo Amarelo coeso distrófico (EMBRAPA, 1999), cujas características químicas, determinadas analiticamente, encontram-se na Tabela 1.

Tabela 1. Análise química do solo na profundidade $0-20 \mathrm{~cm}$, amostrado antes da instalação do experimento

\begin{tabular}{|c|c|c|c|c|c|c|c|c|}
\hline pH & M.0. & ${ }^{*} P$ & $\mathrm{H}+\mathrm{Al}$ & K & $\mathrm{Ca}$ & $\mathrm{Mg}$ & $T$ & V \\
\hline $\mathrm{H}_{2} \mathrm{O}$ & $g \mathrm{dm}^{-3}$ & $\mathrm{mg} \mathrm{m}^{-3}$ & \multicolumn{5}{|c|}{$\mathrm{cmol}_{\mathrm{c}} \mathrm{dm}^{-3}$} & $\%$ \\
\hline 5,5 & 15 & 15 & 3 & 0,05 & 1,8 & 0,8 & 5,7 & 47 \\
\hline
\end{tabular}

O clima, de acordo com a classificação de Koeppen, é do tipo As, tropical chuvoso, com verões secos. Utilizaram-se como parcelas três híbridos de milho (Tork, Fort e BRS-3003) e como subparcelas quatro épocas (dias após a semeadura DAS) para adubação nitrogenada de cobertura, compreendendo os seguintes tratamentos: 1) $120 \mathrm{~kg} \mathrm{ha}^{-1}$ aos 15 DAS, 2) $60 \mathrm{~kg} \mathrm{ha}^{-1}$ aos 5 DAS e $60 \mathrm{~kg} \mathrm{ha}^{-1}$ aos 30 DAS, 3) $120 \mathrm{~kg} \mathrm{ha}^{-1}$ aos 30 DAS, 4) $60 \mathrm{~kg} \mathrm{ha}^{-1}$ aos 30 DAS e $60 \mathrm{~kg} \mathrm{ha}^{-1}$ aos 45 DAS e 5) a testemunha sem adubação nitrogenada (Tabela 2) totalizando, para todos os tratamentos, exceto para a testemunha, $120 \mathrm{~kg} \mathrm{ha}^{-1}$ de $\mathrm{N}$ aplicados na forma de sulfato 
Tabela 2. Tratamentos utilizados no experimento

\begin{tabular}{crcr}
\hline & \multicolumn{3}{c}{ Parcelamentos } \\
\cline { 2 - 4 } Tratamentos & \multicolumn{3}{c}{ dias após a semeadura } \\
\cline { 2 - 4 } & $\mathbf{1 5}$ & $\mathbf{3 0}$ & $\mathbf{4 5}$ \\
\cline { 2 - 4 } 1 & 120 & $\mathbf{k g ~ h a}^{-1}$ & 0 \\
2 & 60 & 0 & 0 \\
3 & 0 & 60 & 0 \\
4 & 0 & 120 & 60 \\
5 & 0 & 60 & 0 \\
\hline
\end{tabular}

de amônio como adubação de cobertura, sendo o adubo distribuído sobre a palhada, ao lado das plantas, ao longo da linha de semeadura.

O delineamento estatístico foi em blocos casualisados com quatro repetições, em esquema de parcelas subdivididas, tendo a área de cada parcela $64 \mathrm{~m}^{2}$ (3,2 x $\left.20 \mathrm{~m}\right)$.

Aplicaram-se no sulco, por ocasião da semeadura, 30, 20, 40 e $4 \mathrm{~kg} \mathrm{ha}^{-1}$ de $\mathrm{N}, \mathrm{P}_{2} \mathrm{O}_{5}, \mathrm{~K}_{2} \mathrm{O}$ e $\mathrm{Zn}$, respectivamente, na forma de sulfato de amônio, superfosfato triplo, cloreto de potássio e sulfato de zinco. No tratamento sem adubação nitrogenada foi suprimida a dose de $\mathrm{N}$. Todas as cultivares são híbridos comerciais, considerados de alta produtividade. Antes da semeadura do milho o solo recebeu calagem, visando elevar a saturação por bases para $70 \%$. Nesta operação foi utilizada $1,4 \mathrm{t} \mathrm{ha}^{-1}$ de calcário dolomítico.

A semeadura do milho foi realizada em 19/10/04, sob vegetação nativa dessecada, utilizando-se semeadora a tração mecanizada, com quatro linhas individuais espaçadas 0,80 m, colocando-se 5 sementes por metro. Realizou-se o controle de plantas daninhas por meio de aplicação de herbicidas de manejo, utilizando-se 2,5 L ha-1 da mistura Glyfosate antes da semeadura do milho e $60 \mathrm{~g} \mathrm{ha}^{-1}$ do ingrediente ativo do herbicida Nicosulfuron em pós-emergência, em um volume de calda de $200 \mathrm{~L} \mathrm{ha}^{-1}$, através de pulverizador de barra tratorizado.

Como o experimento foi conduzido em época atípica à produção de milho no Estado de Alagoas, notou-se a necessidade de suplementação de água através de irrigação em todos os estádios de desenvolvimento da cultura em que a mesma foi determinada com base na evapotranspiração da cultura (ETc) e expressa em mm dia-1.

Esta suplementação se fez oportuna visto que, no período a precipitação pluviométrica da região não atendia às exigências hídricas da cultura, sendo registrados pela Estação Meteorológica CECA/UFAL apenas $94 \mathrm{~mm}$ de chuva no período de outubro de 2004 a janeiro de 2005; toda a água foi fornecida por meio de um sistema de aspersão convencional, com aspersor de pressão de serviço médio (20 m.c.a), típico rotativo movido por impacto do braço oscilante, constituído de dois bocais.

A freqüência de irrigação foi definida pela relação entre a lâmina d'água fornecida e a evapotranspiração da cultura do milho na fase de maior índice de área foliar (estádio fenológico 4), ou seja, com uma lâmina líquida fornecida de $12 \mathrm{~mm}$ e uma ETc de 4,48 $\mathrm{mm} \mathrm{d}^{-1}$ (Teodoro, 2003), perfazendo o turno de rega de 2,67 dias.
Foram utilizados no controle de pragas $75 \mathrm{~mL} \mathrm{ha}^{-1}$ do inseticida Deltamethrin e as formigas controladas preventivamente, com uso de formicidas granulados.

No estádio de florescimento tomaram-se medidas da altura de plantas e diâmetro do colmo; para medidas foram usadas 10 plantas por subparcela, enquanto a colheita foi efetuada 117 dias após a semeadura, ocasião em que se avaliaram os componentes da produção e produtividade de grãos. Os componentes da produção estudados, foram: população final de plantas por hectare, comprimento de espigas, número de fileira de grãos por espigas, número de espigas por hectare e massa de 1000 grãos. Definiu-se a produtividade de grãos colhendo-se todas as espigas da área útil da subparcela, perfazendo área de 4,8 m² (1,6 x $3 \mathrm{~m})$.

Amostras de solo foram coletadas durante o estádio de florescimento do milho, para determinação de $\mathrm{P}$ disponível, K, Ca, Mg, e Al trocáveis, $\mathrm{H}+\mathrm{Al}$, matéria orgânica (M.O) e pH, enquanto as amostras o foram coletadas na profundidade de $0-20 \mathrm{~cm}$, afastadas $20 \mathrm{~cm}$ da planta, na direção das entrelinhas; enfim, as amostras de solo foram analisadas de acordo com a metodologia de análises descrita em EMBRAPA (1997).

Os dados originais foram submetidos análise de variância e as médias dos tratamentos comparadas pelo teste de Tukey a $5 \%$ de probabilidade.

\section{RESULTADOS E DISCUSSÃO}

Os resultados da análise química para a avaliação da fertilidade do solo no estádio de florescimento do milho, encontram-se na Tabela 3; ocorreu melhoria no estado de fertilidade do solo, quando comparados com os resultados da análise, antes da instalação do experimento (Tabela 1) foram notórias as melhorias em algumas características químicas, tais como: aumento do pH, aumento do teor M.O., redução dos teores de $\mathrm{H}+\mathrm{Al}$, elevação de cálcio e magnésio e conseqüentemente, aumento da saturação por base; essas modificações ocorreram em virtude da calagem realizada para elevar a saturação por bases para $70 \%$. Por ocasião do florescimento do milho apenas o potássio não se encontrava em nível satisfatório ao desenvolvimento da cultura.

Tabela 3. Análise química do solo na profundidade $0-20 \mathrm{~cm}$, amostrado no estádio de florescimento da cultura do milho

\begin{tabular}{|c|c|c|c|c|c|c|c|c|}
\hline pH & M.O. & ${ }^{*} P$ & $\mathrm{H}+\mathrm{Al}$ & K & $\mathrm{Ca}$ & $\mathbf{M g}$ & $\mathrm{T}$ & V \\
\hline $\mathrm{H}_{2} \mathrm{O}$ & $\mathrm{g} \mathrm{dm}^{-3}$ & $\mathrm{mg} \mathrm{m}^{-3}$ & \multicolumn{5}{|c|}{$\mathrm{cmol}_{\mathrm{c}} \mathrm{dm}^{-3}$} & $\%$ \\
\hline 7,3 & 16 & 19,9 & 1,8 & 0,05 & 3,0 & 1,55 & 6,4 & 72 \\
\hline
\end{tabular}

Como a área utilizada vinha sendo cultivada com milho nos anos anteriores e se levando em consideração que o potássio é um dos macronutrientes mais absorvidos pela cultura do milho (Barber \& Olson, 1968), vê-se que esta carência já era esperada na fase final do experimento.

Os componentes morfológicos das cultivares estudadas se acham na Tabela 4; quanto à altura de plantas, o tratamento 
2 (60 kg ha-1 aos 15 DAS e $60 \mathrm{~kg} \mathrm{ha}^{-1}$ aos 30 DAS) não diferiu estatisticamente dos tratamentos $1\left(120 \mathrm{~kg} \mathrm{ha}^{-1}\right.$ aos 15 DAS) e 3 (120 kg ha-1 aos 30 DAS). O tratamento 4 (60 kg ha-1 aos 30 DAS e $60 \mathrm{~kg} \mathrm{ha}^{-1}$ aos 45 DAS) também não diferiu dos tratamentos 1 e 3 . A testemunha, por sua vez, apresentou diferença significativa quando comparada a todos os outros tratamentos; esses resultados mostram que em condições climáticas satisfatórias, as aplicações de doses de $\mathrm{N}$ totais ou parceladas não implicarão em diferenças significativas, devido ao fato do nitrogênio estar associado, dentre outras funções na planta, ao crescimento vegetativo (Karlen et al., 1988). O N é importante no estádio inicial de desenvolvimento da planta ( $2^{\mathrm{a}}$ semana após a emergência), quando ela está com quatro folhas totalmente desdobradas, pois esta é a fase em que o sistema radicular, em desenvolvimento, já mostra considerável porcentagem de pêlos absorventes e ramificações diferenciadas, e a adição de N estimula sua proliferação, com conseqüente desenvolvimento da parte aérea (Fancelli, 1997).

Segundo Souza et al. (2003) a altura de plantas é uma característica genética, influenciada pelo ambiente no qual a planta se desenvolve.

Os dados encontrados neste experimento discordam dos obtidos por Gross et al. (2006) que, ao estudarem quatro épocas de aplicação da adubação nitrogenada em cobertura para o milho, obtiveram diferença significativa para a altura de plantas. As maiores médias ocorreram quando se realizaram duas aplicações com 4-5 folhas e 7-8 folhas ou quando toda a cobertura foi aplicada e a planta estava com 6-7 folhas, em comparação com tratamento sem cobertura ou com a cobertura aplicada logo após a semeadura.

Com relação ao diâmetro do colmo, o tratamento 1 (120 kg ha-1 aos 15 DAS) não diferiu estatisticamente apenas do tratamento 2 (60 kg ha-1 aos 15 DAS e $60 \mathrm{~kg} \mathrm{ha}^{-1}$ aos 30 DAS) que, por sua vez, não apresentou diferença quando comparado com o 3 (120 kg ha-1 aos 30 DAS), sendo o tratamento 4 (60 $\mathrm{kg} \mathrm{ha}^{-1}$ aos 30 DAS e $60 \mathrm{~kg} \mathrm{ha}^{-1}$ aos 45 DAS) e a testemunha diferentes estatisticamente entre si e entre os demais, ou seja, ocorreu aumento a medida em que a aplicação de $\mathrm{N}$ em cobertura se aproximou dos 15 dias após a semeadura.

De acordo com Fancelli \& Dourado-Neto (2000), o colmo atua também como estrutura de armazenamento de sólidos solúveis que serão utilizados posteriormente na formação dos grãos.

Tabela 4. Componentes morfológicos do milho em Sistema Plantio Direto (SPD) nos tabuleiros costeiros do Estado de Alagoas

\begin{tabular}{ccc}
\hline Tratamentos $^{(1)}$ & $\begin{array}{c}\text { Altura da Planta } \\
\mathbf{m}\end{array}$ & $\begin{array}{c}\text { Diâmetro do Colmo } \\
\mathbf{m m}\end{array}$ \\
1 & $1,70 \mathrm{AB}$ & $25,25 \mathrm{~A}$ \\
2 & $1,72 \mathrm{~A}$ & $24,37 \mathrm{AB}$ \\
3 & $1,70 \mathrm{AB}$ & $23,35 \mathrm{~B}$ \\
4 & $1,60 \mathrm{~B}$ & $21,70 \mathrm{C}$ \\
5 & $1,24 \mathrm{C}$ & $18,32 \mathrm{D}$ \\
DMS & 0,10 & 1,15 \\
CV\% & 4,79 & 3,67 \\
\hline
\end{tabular}

(1) 1) $120 \mathrm{~kg} \mathrm{ha}^{-1}$ aos 15 DAS, 2) $60 \mathrm{~kg} \mathrm{ha}^{-1}$ aos 15 DAS e $60 \mathrm{~kg} \mathrm{ha}^{-1}$ aos $\left.30 \mathrm{DAS}, 3\right) 120 \mathrm{~kg} \mathrm{ha}^{-1}$ aos 30 DAS, 4) $60 \mathrm{~kg} \mathrm{ha}^{-1}$ aos $30 \mathrm{DAS}^{\mathrm{N}} 60 \mathrm{~kg} \mathrm{ha}^{-1}$ aos 45 DAS e 5) a testemunha sem adubação nitrogenada. Médias seguidas de letras diferentes na coluna diferem estatisticamente pelo Teste de Tukey a $5 \%$ de probabilidade
Os componentes da produção dos cultivares estudados estão na Tabela 5. Na população final de plantas apenas a testemunha variou significativamente em relação aos demais tratamentos utilizados, fato provocado pela deficiência de nitrogênio, um dos principais constituintes de toda a molécula e que, quando ausente ou em níveis baixos na planta, provoca o retardamento do crescimento da parte aérea (Malavolta et al., 1997). Nesse experimento, essa deficiência afetou significativamente a população final de plantas. O número de espigas, conseqüentemente, apresentou o mesmo comportamento da população final de plantas, já que o índice de espiga indicou comportamento semelhante variando de 0,80 e 0,55 para todos os tratamentos.

Tabela 5. Componentes da produção de três cultivares de milho em Sistema Plantio Direto (SPD) nos Tabuleiros Costeiros do Estado de Alagoas

\begin{tabular}{|c|c|c|c|c|c|c|}
\hline Trat. & $\begin{array}{c}\text { População } \\
\text { de plantas } \\
\text { plantas } \\
\text { ha }^{-1}\end{array}$ & $\begin{array}{c}\text { No de } \\
\text { Espigas } \\
\text { espigas } \\
\text { ha }^{-1}\end{array}$ & $\begin{array}{c}\text { Fileiras } \\
\text { de grãos } \\
\text { Fileiras } \\
\text { espiga }^{-1}\end{array}$ & $\begin{array}{c}\text { Comp. } \\
\text { de espiga } \\
\text { cm }\end{array}$ & $\begin{array}{c}\text { Massa } \\
\text { de } 1000 \\
\text { grãos } \\
\text { g }\end{array}$ & $\begin{array}{l}\text { Prod. } \\
\text { de grãos } \\
\mathrm{kg} \mathrm{ha}^{-1}\end{array}$ \\
\hline *1 & $65.979 \mathrm{~A}$ & $48.375 \mathrm{~A}$ & $15,62 \mathrm{~A}$ & $14,83 \mathrm{~A}$ & $280,91 \mathrm{~A}$ & $7.153 \mathrm{~A}$ \\
\hline 2 & $65.270 \mathrm{~A}$ & $52.312 \mathrm{~A}$ & $15,07 \mathrm{AB}$ & $13,38 \mathrm{CD}$ & $290,21 \mathrm{~A}$ & $6.632 \mathrm{~A}$ \\
\hline 3 & $65.500 \mathrm{~A}$ & $50.916 \mathrm{~A}$ & $14,44 \mathrm{BC}$ & $14,69 \mathrm{AB}$ & 290,49 A & $7.292 \mathrm{~A}$ \\
\hline 4 & $64.125 \mathrm{~A}$ & $51.854 \mathrm{~A}$ & $14,49 \mathrm{BC}$ & $12,84 \mathrm{D}$ & $290,38 \mathrm{~A}$ & $6.933 \mathrm{~A}$ \\
\hline 5 & 52.771 B & 29.166 B & $13,87 \mathrm{C}$ & $13,97 \mathrm{BC}$ & 220,75 B & $2.188 \mathrm{~B}$ \\
\hline DMS & 2.279 & 4.039 & 0,82 & 0,86 & 20,04 & 1.151 \\
\hline CV\% & 5,45 & 13,01 & 4,02 & 5,47 & 5,26 & 13.71 \\
\hline
\end{tabular}

(*) 1) $120 \mathrm{~kg} \mathrm{ha}^{-1}$ aos 15 DAS, 2) $60 \mathrm{~kg} \mathrm{ha}^{-1}$ aos 15 DAS e $60 \mathrm{~kg} \mathrm{ha}^{-1}$ aos 30 DAS, 3) $120 \mathrm{~kg} \mathrm{ha}^{-1}$ aos 30 DAS, 4) $60 \mathrm{~kg} \mathrm{ha}^{-1}$ aos 30 DAS e $60 \mathrm{~kg} \mathrm{ha}^{-1}$ aos 45 DAS e 5) a testemunha sem adubação nitrogenada. Médias seguidas de letras diferentes na coluna diferem estatisticamente pelo Teste de Tukey a $5 \%$ de probabilidade

Os valores médios do número de fileiras de grãos por espiga apresentaram efeitos significativos entre os diferentes tratamentos. O tratamento 1 (120 kg ha-1 aos 15 DAS) não diferiu do tratamento $2\left(60 \mathrm{~kg} \mathrm{ha}^{-1}\right.$ aos 15 DAS e $60 \mathrm{~kg} \mathrm{ha}^{-1}$ aos 30 DAS) e foi superior aos demais. Os tratamentos 3 (120 kg ha-1 aos 30 DAS) e $4\left(60 \mathrm{~kg} \mathrm{ha}^{-1}\right.$ aos 30 DAS e $60 \mathrm{~kg} \mathrm{ha}^{-1}$ aos 45 DAS) não diferiram da testemunha. A aplicação de $120 \mathrm{~kg} \mathrm{ha}^{-1} \mathrm{~N}$ aos 15 DAS beneficiou este componente quando comparado com a aplicação ao da mesma dose aplicada aos 30 DAS. O parcelamento da adubação aos 15 e 30 DAS não diferiu da aplicação da dose cheia aos 15 DAS mas, sim do parcelamento aos 30 e 45 DAS, cujos resultados mostram que o número de fileiras de grãos por espiga foi influenciado pela adubação aos 15 DAS, independentemente do parcelamento.

Resultados obtidos por Novais et al. (1974) sobre o parcelamento do nitrogênio na cultura do milho, mostram que o não suprimento deste nutriente durante a fase inicial de desenvolvimento vegetativo, com aplicação de toda a dose no florescimento (65 DAS), assim como o excessivo número de aplicações parceladas, apresentou menor eficiência que a aplicação por ocasião da semeadura e na fase de desenvolvimento vegetativo.

Para os valores médios da massa de 1000 grãos os tratamentos que receberam adubação nitrogenada não diferiram entre si e foram superiores à testemunha. A deficiência de $\mathrm{N}$ 
afetou, de forma expressiva, este componente. Para o nitrogênio, o milho apresenta dois períodos de máxima absorção durante as fases de desenvolvimento vegetativo e reprodutivo ou formação da espiga (Olness \& Benoit, 1992). De acordo com (Malavolta et al., 1997), a deficiência de N provoca o retardamento do crescimento da parte aérea, interferindo na translocação de nutrientes no processo de enchimento de grãos, fato este visível no presente trabalho; fica claro, também, que a época de aplicação e os parcelamentos utilizados no presente trabalho não foram fatores limitantes para este componente.

A massa de 1000 grãos pode ser modificada, segundo Rambo et al. (2004), devido à variabilidade de condições meteorológicas e de solo, associada aos múltiplos processos que interferem na complexa dinâmica do $\mathrm{N}$ no solo (lixiviação, volatilização, imobililização, mobilização, nitrificação, desnitrificação e mineralização) e na sua relação com a planta, que podem ocasionar grandes modificações na disponibilidade e na necessidade desse nutriente durante a ontogenia da cultura.

As produtividades de grãos obtidas não apresentaram diferenças significativas entre os tratamentos que receberam adubações nitrogenadas, independentes da época e parcelamento utilizado; referidos dados discordam daqueles encontrados por Silva et al. (2005) os quais relataram que a produtividade do milho foi afetada pelas épocas de aplicação da adubação nitrogenada, em que as aplicações de todo o $\mathrm{N}$ na semeadura e aos 15 dias após a emergência (DAE) se mostraram superiores quando comparadas com a aplicação aos 35 DAE; este impasse desfavoreceu, certamente, a imobilização do N pelos microrganismos quimiorganotróficos para a decomposição dos resíduos da aveia preta e das plantas daninhas (Sá, 1996; Ceretta et al., 2002 apud Silva et al., 2005); por outro lado isto teria condicionado a uma maior e mais contínua disponibilidade de $\mathrm{N}$ mineral na solução do solo, provocando maior aproveitamento do $\mathrm{N}$ pelo milho e maior resposta em produtividade de grãos (Amado et al., 2002).

Basso et al. (1998), estudando o manejo do $\mathrm{N}$ no milho cultivado no sistema plantio direto, visando aumentar a sua disponibilidade nos estádios iniciais de desenvolvimento da cultura, observaram que quando se aplicaram 60-30$30 \mathrm{~kg} \mathrm{ha}^{-1} \mathrm{~N}$ em pré-semeadura, semeadura e cobertura, respectivamente, ou seja, $75 \%$ do $\mathrm{N}$ total recomendado aplicado até a semeadura, obtiveram-se o maior rendimento de grãos de milho, comparado ao manejo tradicional (semeadura + cobertura), mostrando uma eficiência maior na utilização do N quando se aumenta sua disponibilidade no desenvolvimento inicial do milho.

Pöttker \& Wiethölter (2004) estudando épocas e métodos de aplicação de nitrogênio em milho cultivado no sistema plantio direto (aplicação de $\mathrm{N}$ antes da semeadura, geralmente 10 dias após a dessecação da aveia, aplicações na semeadura e na semeadura + cobertura) obtiveram o maior rendimento de grãos de milho nos dois tratamentos que receberam adubação em cobertura, enquanto todos os demais tratamentos apresentaram rendimentos estatisticamente inferiores e semelhantes entre si.

\section{CONCLUSÕES}

O parcelamento da adubação nitrogenada de cobertura não se faz necessário no sistema plantio direto nos Tabuleiros Costeiros do Estado de Alagoas.

\section{LITERATURA CITADA}

Amado, T. J. C.; Mielniczuk, J.; Aita, C. Recomendação de adubação nitrogenada para o milho no RS e SC adaptada ao uso de culturas de cobertura do solo, sob sistema plantio direto. Revista Brasileira Ciência do Solo, v.26, n.1, p.241-248, 2002.

Barber, S. A.; Olson, R. A. Fertilizer use on corn. In: Nelson, L. B. et al. (eds): Changing patterns in fertilizer use. Madison: Soil Science Society of America, 1968, p.275-295.

Basso, C. J.; Ceretta, C. A.; Marcolan, A. L.; Durigon, R. Manejo do nitrogênio no milho cultivado em sucessão a plantas de cobertura de solo no inverno, no sistema plantio direto. In: Reunião Brasileira de Fertilidade do Solo e Nutrição de Plantas, 23, 1998. Caxambu. Resumos... Lavras: UFLA, SBCS, SBM, 1998. p.145.

Bayer, M. M.; Todd, C. D.; Hoyle, J. E.; Wilson, J. F. B. Waverelated abrasion induces formation of extended spines in a marine bryozoan. Proceedings of the Royal Society of London, Series B, 264, p.1605-1611. 1997.

Coelho, A. M; França, G. E. de; Bahia Filho, A. F. C. Nutrição e adubação do milho. http://www.cnpms.embrapa.br/publicacoes/ milho/feraduba.htm>. 23 Jan. 2006.

Cruz, J. C.; Pereira, F. T. F. P.; Pereira Filho, I. A.; Coelho, A. M. Resposta de cultivares de milho à adubação nitrogenada em cobertura. Sete Lagoas: EMBRAPA. Dezembro, 2005. p.65 Comunicado Técnico 116.

EMBRAPA - Empresa Brasileira de Pesquisa Agropecuária. Sistema Brasileiro de Classificação de Solos. Brasília: Embrapa Produção da Informação; Rio de Janeiro: Embrapa Solos, 1999. 412p.1999. 412p.

EMBRAPA - Empresa Brasileira de Pesquisa Agropecuária. Centro Nacional de Pesquisa de Solos. Manual de métodos de análise de solos. 2.ed. Rev. e Atual. Rio de Janeiro: EMBRAPA, 1997. 212p.

Fancelli, A. L. Cultura do milho: A importância da tecnologia. Informações Agronômicas, n.78, p.4-6, 1997.

Fancelli, A. L.; Dourado-Neto, D. Produção de milho. Guaíba: Agropecuária, 2000. 360p.

França, G. E.; Coelho, A. M.; Bahia Filho, A. F. C. Parcelamento da adubação nitrogenada em cobertura na cultura do milho irrigado. In: Congresso Nacional de Milho e Sorgo, 20, 1994. Goiânia. Resumos... Goiânia: ABMS; EMBRAPA CNPMS; UFG; EMATER-GO, 1994. p.101.

Gonçalves, C. N.; Cereta, C. A.; Basso, C. J. Sucessões de culturas com plantas de cobertura e milho em plantio direto e sua influência sobre o nitrogênio do solo. Revista Brasileira de Ciência do Solo, v.24, n.1, p.153-159, 2000.

Gross, M. R.; Pinho, R. G. V.; Brito, A. H. de. Adubação nitrogenada, densidade de semeadura e espaçamento entre fileiras na cultura do milho em sistema plantio direto. Ciência Agrotécnica, v.30, n.3, p.387-393, 2006. 
Haper, L. H.; Shape, R. R. Nitrogen dynamics in irrigated corn: soil-plant nitrogen end atmosphere ammonia transport. Agronomy Journal, v.87, n.31, p.669-675, 1995.

Karlen, D. L.; Flanery, R. L.; Sadler, E. J. Aerial accumulation and partitioning of nutrients by corn. Agronomy Journal, v.80, n.2, p.232-42, 1988.

Lara Cabezas, W. A. R.; Trivelin, P. C. O.; Kornodôrf, G. H.; Pereira, S. Balanço da adubação nitrogenada sólida e fluida de cobertura na cultura do milho em sistema plantio direto no Triângulo Mineiro. Revista Brasileira de Ciência do Solo, v.14, n.2, p.363-376, 2000.

Machado, E. C.; Pereira, A. R.; Fahl, J. I.; Arruda, H. V.; Silva, W. J.; Teixeira, J. P. F. Análise quantitativa de crescimento de quatro variedades de milho em três densidades, através de funções matemáticas ajustadas. Pesquisa Agropecuária Brasileira, v.17, n.6, p.825-833, 1982.

Magalhães, A. C. N. Análise quantitativa de crescimento. In: Ferri, M. G. (ed.) Fisiologia Vegetal. São Paulo: EDSP, 1979. v.1, p.331-349.

Malavolta, E.; Vitti, G. C.; Oliveira, S. A. Avaliação do estado nutricional das plantas: Princípios e aplicação. 2.ed. Piracicaba: POTAFOS, 1997. 319p.

Müller Mai. M. E.; Ceretta, C. A.; Basso, C. J.; Silveira, M. J. da; Pavinato, A.; Pavinato, P. F. Manejo da adubação nitrogenada na sucessão aveia-preta/milho no sistema plantio direto. Pesquisa Agropecuária Brasileira, v.38 n.1, p.125-131, 2003.

Neumann, M.; Sndini, I. E.; Lustosa, S. B. C.; Ost, P. R.; Romano, M. A.; Falbo, M. K.; Pansera, E. R. Rendimentos e componentes de produção da planta de milho (Zea mays L.) para silagem, em função de níveis de adubação nitrogenada em cobertura. Revista Brasileira de Milho e Sorgo, v.4, n.3, p.418-427, 2005.
Novais, M. V.; Novais, R. F.; Braga, J. M. Efeito da adubação nitrogenada e de seu parcelamento sobre a cultura do milho, em Patos de Minas. Revista Ceres, v.21, n.115, p.193-202, 1974.

Olness, A.; Benoit, G. R. A closer look at corn nutrient demand. Better Crops with Plant Food, v.76, n.2, p.18-20, 1992.

Pöttker, D.; Wiethölter, S. Épocas e métodos de aplicação de nitrogênio em milho cultivado no sistema plantio direto. Ciência Rural, v.34, n.4, p.1015-1020, 2004.

Rambo, L.; Silva, P. R. F.; Argenta, G.; Sangoi, L. Parâmetro de plantas para aprimorar o manejo da adubação nitrogenada de cobertura de milho. Ciência Rural, v.34, n.5, p.16371645, 2004.

Sá, J. C. M. Sistema de produção de milho visando alta produtividade na região dos campos gerais no centro-sul do Paraná. In: Büll, L. T.; Cantarela, H. Cultura do milho: Fatores que afetam a produtividade. Piracicaba: POTAFOS, 1993, 301p.

Silva, E. C. da; Ferreira, S. M.; Silva, G. P.; Assis, R. L. de, Guimarães, G. L. Épocas e formas de aplicação de nitrogênio no milho sob plantio direto em solo de cerrado. Revista Brasileira de Ciência do Solo, v.29 n.5, p.725-733, 2005.

Souza, L. C. F.; Fedatto, E.; Gonçalves, M. C.; Sobrinho, T. A.; Hoogerheide, H. C.; Vieira, V. V. Produtividade de grãos de milho irrigado em função da cultura antecessora e de doses de nitrogênio. Revista Brasileira de Milho e Sorgo, v.2, n.2, p.44-51, 2003.

Teodoro, I. Avaliação energética e hídrica no desenvolvimento da cultura do milho irrigado, na Região de Rio Largo, AL. 2003. Rio Largo: UFAL, 2003. 108p. Dissertação Mestrado

Vasconcelos, C. A.; Viana, M. C. M.; Ferreira, J. J. Acúmulo de matéria seca e de nutrientes em milho cultivado no período de inverno-primavera. Pesquisa Agropecuária Brasileira, v.33, n.11, p.1835-1845, 1998. 